\title{
RESEARCH
}

Open Access

\section{Effects of medicaid expansion on poverty disparities in health insurance coverage}

\author{
Yilu Lin, Alisha Monnette and Lizheng Shi ${ }^{*}$
}

\begin{abstract}
Background: More than 30 states have either expanded Medicaid or are actively considering expansion. The coverage gains from this policy are well documented, however, the impacts of its increasing coverage on poverty disparity are unclear at the national level.

Method: American Community Survey (2012-2018) was used to examine the effects of Medicaid expansion on poverty disparity in insurance coverage for nonelderly adults in the United States. Differences-in-differences-indifferences design was used to analyze trends in uninsured rates by poverty levels: (1) < 138\%, (2) 138-400\% and (3) $>400 \%$ federal poverty level (FPL).
\end{abstract}

Results: Compared with uninsured rates in 2012, uninsured rates in 2018 decreased by $10.75 \%, 6.42 \%$, and $1.11 \%$ for $<138 \%, 138-400 \%$, and $>400 \% \mathrm{FPL}$, respectively. From 2012 to $2018,>400 \% \mathrm{FPL}$ group continuously had the lowest uninsured rate and $<138 \%$ FPL group had the highest uninsured rate. Compared with $\geq 138 \% \mathrm{FPL}$ groups, there was a $2.54 \%$ reduction in uninsured risk after Medicaid expansion among $<138 \%$ FPL group in Medicaid expansion states versus control states. After eliminating the impact of the ACA market exchange premium subsidy, $3.18 \%$ decrease was estimated.

Conclusion: Poverty disparity in uninsured rates improved with Medicaid expansion. However, $<138 \% \mathrm{FPL}$ population are still at a higher risk for being uninsured.

Keywords: Health equity, Medicaid expansion, Poverty disparity, Insurance coverage

\section{Background}

Large disparities in health insurance coverage, related to poverty, have been a long-standing issue in the United States (US) and a significant concern among policymakers and health care professionals. According to the Kaiser Family Foundation, as of 2019, individuals under $200 \%$ FPL accounted for $30 \%$ of the total US population [1]. This large proportion of low-income individuals signifies a need to investigate the disparities in poverty and insurance coverage, and more specifically, how healthcare reform has impacted coverage. Long-standing disparities in coverage have consistently been a topic of

\section{* Correspondence: Ishi1@tulane.edu}

Department of Health Policy and Management, School of Public Health and Tropical Medicine, Tulane University, 1440 Canal Street, Suite 1900, Louisiana 70112 New Orleans, USA discussion with multiple factors being considered as the cause for such differences. On one hand, studies have identified insurance coverage as an important determinant for disparities in access to care [2,3]. While, lack of health care access and insurance coverage could be major contributors to poverty disparities, as this decreases one's quality of life due to prolonged negative impacts of poverty and insurance status $[4,5]$. Policies that reduce disparities in health insurance coverage are likely to have a broader effect on economic inequality [6]. Thus, it is imperative to examine the role of poverty and its association with access to care, to gain a deeper understanding of the disparities in the healthcare sector in order to improve health equity.

Implemented in 2014, evidence of the Affordable Care Act (ACA) showed a significant decrease in the uninsured

(c) The Author(s). 2021 Open Access This article is licensed under a Creative Commons Attribution 4.0 International License, which permits use, sharing, adaptation, distribution and reproduction in any medium or format, as long as you give appropriate credit to the original author(s) and the source, provide a link to the Creative Commons licence, and indicate if changes were made. The images or other third party material in this article are included in the article's Creative Commons licence, unless indicated otherwise in a credit line to the material. If material is not included in the article's Creative Commons licence and your intended use is not permitted by statutory regulation or exceeds the permitted use, you will need to obtain permission directly from the copyright holder. To view a copy of this licence, visit http://creativecommons.org/licenses/by/4.0/ The Creative Commons Public Domain Dedication waiver (http://creativecommons.org/publicdomain/zero/1.0/) applies to the data made available in this article, unless otherwise stated in a credit line to the data. 
rate from 18 to $12 \%$ [7]. The expansion of health insurance, both public and private, resulted in a net increase of 16.9 million people gaining coverage between 2013 and 2015 , allowing millions of previously uninsured individuals to access and utilize health care services [8]. The Medicaid expansion provision and the ACA market exchange subsidy contributed greatly to this sharp decline. As one of the major provisions of ACA, Medicaid expansion reduced health inequity by increasing access to health insurance coverage among low-income populations, who were at high risk of being uninsured. Medicaid expansion expanded the enrollment eligibility criteria for Medicaid to 138 \% Federal Poverty Level (FPL), [9] resulting in gains in coverage for millions of low-income adults in more than 30 states [10]. After the debate on whether to expand Medicaid vs. weighing alternative approaches (i.e. using private insurance or increasing cost-sharing), more states have continued to expand Medicaid because data shows that low-income individuals who have historically experienced suboptimal access to care or gone without coverage, can benefit greatly from expansion [11-13].

Previous literature has examined the impact of Medicaid Expansion across various vulnerable populations (i.e. young mothers including pregnant women, veterans, people with disabilities, people with obesity, smokers, and immigrants) [14-20], disease conditions (i.e. cancers, AIDS and mental diseases) [21-30], sociodemographics [31, 32], and healthcare services (i.e. inpatient, outpatient and preventive services) [33-36], after the policy was implemented. Additionally, statelevel analyses have been conducted to assess the impacts of expansion, as Kentucky and Indiana have been well discussed [37, 38].

Regarding the policy impact on insurance coverage rates and healthcare access, several researchers have examined this topic and concluded that the rate of persons insured increased due to Medicaid expansion in all cases. Huguet and colleagues examined the changes in uninsured visits across 412 primary care community health centers using electronic health records between 2012 and 2015 [39]. Blumberg et al. (2016) provided an overview of the characteristics of newly insured due to the ACA and those remaining uninsured in 2016 [40]. Other studies analyzed the insurance coverage gain of Medicaid expansion along with ACA by 2015 or 2016 [41-45]. Across each of these studies, researchers found that the rate of persons insured increased due to Medicaid expansion in all cases.

However, these studies only restricted the policy impact to the first- and second- year following Medicaid expansion in 2014 and did not distinguish Medicaid Expansion from other ACA provisions (i.e., market exchange subsidy, young adults remaining on parents' health insurance plans until they reach age 26 , etc.). The
ACA market exchange subsidy eligibility is based on income, where individuals must earn at least $100 \%$ FPL (above $138 \%$ FPL in states that have expanded Medicaid), but no more than $400 \%$ FPL. This premium subsidy can increase access to insurance for those between 100 and $400 \%$ FPL. Therefore, it must be distinguished from the Medicaid expansion provision when analyzing the Medicaid expansion policy alone. Additionally, as different states adopted Medicaid expansion at different times, the dynamic effects seen across adoption of the policy have not been clearly examined in previous research.

To address these gaps, this study aimed to document changes in health insurance coverage for nonelderly US adults, aged 26-64, from 2012 to 2018 and evaluate the effects of the dynamic adoption of Medicaid expansion on poverty disparities in health insurance coverage at the national level. With a longer post-policy period, our study aimed to use causal inference to capture precise estimations of the sole effects of the Medicaid Expansion provision.

\section{Conceptual Model}

To address this study objective, the Andersen Behavioral Model for access to health care, derived from the original Anderson Healthcare Utilization Model, was adapted for this study [46]. This model illustrates that there are certain factors that increase one's likelihood of using health care services and these are determined by three mechanisms of action: predisposing factors, enabling factors, and need. "Predisposing factors" are defined as demographic variables such as age, sex, race/ethnicity, marital status, education, employment, and poverty/income. The "enabling factor" in this study would be insurance coverage, and the "need" is access to health care services (Fig. 1).

\section{Methods \\ Data}

This study used publicly available data that was waived from review by the Institutional Review Board at Tulane University. Data analysis was based on repeated crosssectional national population level data from the 20122018 7-year American Community Survey (ACS) Public Use Microdata Sample (PUMS) files. ACS is a very large survey, in terms of number of respondents who complete the survey, making it possible to obtain estimations for narrowly defined subpopulations by FPL [47]. PUMS are a sample of actual responses from the ACS and include most population and housing characteristics. This data source, with the flexibility to prepare customized tabulations, can be used for detailed research and analysis. In the PUMS, files have been de-identified to protect the confidentiality of all individuals and 


\section{Anderson Model}

\section{Predisposing \\ Factors}

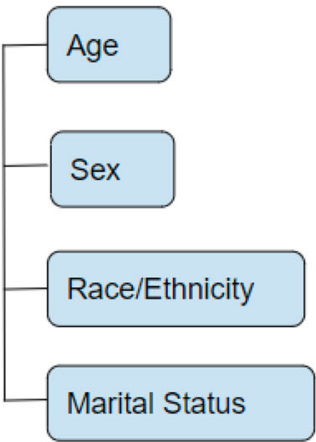

Enabling Factors

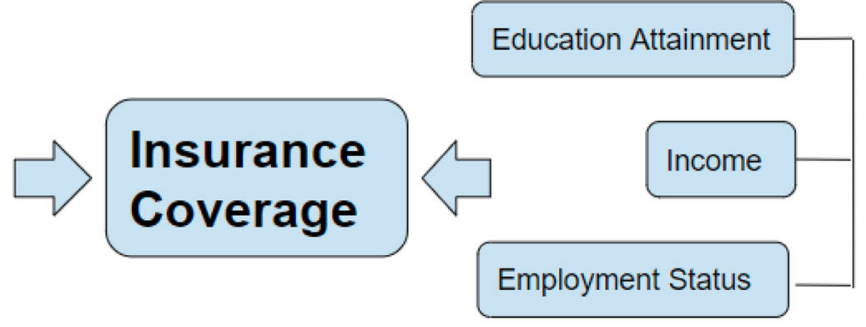

Fig. 1 Conceptual Framework: Anderson Model

households. Further, this survey includes information about socio-economic, demographics, and other characteristics. The PUMS file contains over 3.5 million respondents each year with an average response rate of over $97 \%$. The differences in this cross-sectional survey were constant over time, which makes the estimation of trends in insurance coverage comparable [48].

\section{Analytic Strategy}

This study employed differences-in-differences-in-differences (triple-D) design by comparing the outcome (health insurance coverage), before and after the intervention (implementation of Medicaid expansion) for the treatment group (individuals under 138 \% FPL) and control group. This quasi-experimental design has been widely used to estimate the effects of a specific intervention or treatment by comparing the changes in outcomes over time between a population that is enrolled in a policy/program (i.e. the intervention group) and a population that is not (i.e. the control group) $[49,50]$. The approach removes biases in post-policy period comparisons between the treatment and control group that could be the result from permanent differences between those groups, as well as biases from comparisons over time in the treatment group that could be the result of trends due to other causes of the outcome.

In this study, we did not include data prior to 2012 and excluded individuals less than 26 years old, as a provision of the ACA enables young adults to remain on their parents' insurance plans until 26 years old. Without capturing effects of that provision, which have been well studied in previous research, our results excluded this potential confounding impact [51-53]. Additionally, a 0 to 1 intensity was used to demonstrate the effect of the dynamic enrollment of adoption of the policy for each state in order to generate more precise estimates.

The first regression was performed with the entire sample, with the treatment group being those under $138 \%$ FPL and the control group being those with FPL above $138 \%$. The second regression included those under $138 \%$ FPL as the treatment group and those above $400 \%$ FPL as the control group. Those with an FPL range from 138 to $400 \%$ were excluded in order to eliminate the ACA market exchange subsidy influence on the insurance coverage rate. The equation is as follows:

$$
\begin{aligned}
\text { (1) } \text { Uninsured }_{i s y}= & \beta_{0}+\beta_{1} \text { Expanded }_{i s y}+\beta_{2} \gamma_{s y} \\
& +\beta_{3} \delta_{i s}+\beta_{4} \eta_{i y}+\beta_{5} \text { Poverty }_{i s y} \\
& +\beta_{6} \text { State }_{i y}+\beta_{7} \text { Year }_{i s}+\beta_{5} X_{i s y}+\epsilon_{i s y}
\end{aligned}
$$

(2) Expanded $_{i s y}=$ Medicaid_Expansion ${ }_{s y} *$ Poverty $_{i s y}$

\section{Variables and Measures}

Uninsured $_{\text {isy }}$ was the study outcome. It was derived by the survey question "whether the individual has any insurance coverage" and was transformed into a 
dichotomous variable where 1 equaled no health insurance and 0 equaled having any insurance.

Expanded $_{i s y}$, variable of interest, was the interaction term that measured the individual level of Medicaid expansion status. This variable was calculated by

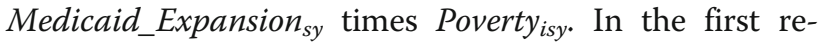
gression, the coefficient of this variable reflected the impact Medicaid expansion had on insurance coverage between persons below 138\% FPL (treatment group) and above $138 \%$ FPL (control group) in year $i$ and state $s$. In the second regression, the control group were the individuals above $400 \%$ FPL.

Medicaid_Expansion $n_{s y}$ was the Medicaid expansion policy indicator variable, defined as a varying intensity variable from 0 to 1 . When a state expanded Medicaid, this variable equaled 1 , otherwise, it equaled 0 . For states that adopted the policy at the beginning of the year, time before this certain year was the pre-policy period and from this year to 2018 was the post-policy period. Coverage under Medicaid expansion became effective January 1, 2014 in all states that adopted the policy except the following: Michigan (4/1/2014), New Hampshire (8/15/2014), Pennsylvania (1/1/2015), Indiana (2/1/ 2015), Alaska (9/1/2015), Montana (1/1/2016), Louisiana $(7 / 1 / 2016)$ [54]. For the above states, the indicator variable was coded as the portion of the year and then equaled to 1 in the following post-policy period. Specifically, the treatment for Michigan in 2014 was 275/365; the treatment for New Hampshire in 2014 was 138/365; the treatment for Indiana in 2015 was 334/365; the treatment for Alaska in 2015 was 122/365; and the treatment for Louisiana in 2016 was 184/365. Substantive Medicaid expansion policies prior to the state's official implementation date of Medicaid expansion were not considered in the study. However, the prior adoption of Medicaid expansions in some states (IN, ME, TN, and WI) were quite limited with capped or closed enrollment. In some states a mild form of Medicaid expansion was adopted prior to the enactment of the ACA for both parents and childless adults (DE, DC, MA, NY, VT), which turned out to be an equivalent of the ACA expansion.

Poverty $_{i s y}$, was defined as a categorical variable using FPL threshold. FLP was calculated using poverty guidelines (one of the federal poverty measures) and the number of persons living in a household [55]. The poverty guidelines are updated each year by the US Department of Health and Human Services, for use for administrative purposes (e.g., determining financial eligibility for federal Medicaid programs). In the first regression, $138 \%$ FPL was used as the cut-off point, where 1 was the population below $138 \%$ FPL and 0 represented the population above $138 \%$ FPL (control group). In the second regression, 1 represented those below $138 \%$ FPL and 0 represented those above $400 \%$ FPL (control group).

$\gamma_{s y}$ was the interaction term for year and state. $\delta_{i s}$ was the interaction term for whether the individual was under $138 \%$ FPL in a specific state. $\eta_{i y}$ was the interaction term for whether the individual was under $138 \%$ FPL in a specific year (2012-2018).State ${ }_{i y}$ indicated the residence of state for the individuals in a given year. Year $_{i s}$ represented the calendar year for the individuals in a state.

$X_{i s y}$ was a series of individual demographic and socioeconomic covariates based on the Andersen model. Age, sex, race/ethnicity, marital status, education attainment, and employment status were adjusted in each model and these variables have been widely used in the literature to examine health care access and utilization $[4,5,56,57]$. Age was measured as a categorical variable: $26-34,35-$ $44,45-54$ and 55-64. Sex was also a categorical variable, where 1 was male and 0 was female. Survey participants were asked to self-report their race (White, Black/African American, American Indian/Alaska Native, Asian, Native Hawaiian/other Pacific islander, or multiple race) and ethnicity (Hispanic/Latino: yes/no) separately. A 4category race/ethnicity variable was coded as follows: participants reporting Hispanic/Latino ethnicity were considered Hispanic, regardless of race; all nonHispanics were categorized as White, Black, or other races. Thus, Whites were coded as 0 , Blacks, Hispanics, and Others were coded as 1, 2 and 3, respectively. Marital status was self-reported and categorized as married, widowed, divorced, and separated, and never married. For the model, we coded married as 0 and combined widowed, divorced, and separated into one group, and coded this group as (1) Self-identified education level was grouped by less than high school coded as 0 , high school graduate, GED, or alternative coded as 1 , and bachelor's degree or higher coded as (2) Current employment status was categorized as unemployed coded as 0 , employed coded as 1 , and not in the labor force coded as 2.

Robustness checks were performed to test whether Medicaid expansion had an effect [58, 59]. To test this, we verified whether the control group (individuals with $<138 \%$ FPL in non-expansion states) served as a good comparison for the treatment group (individuals with $<$ 138 \% FPL in states that expanded Medicaid). Therefore, we tested if the trends in the two groups were parallel before the policy was implemented. This assumption was tested indirectly by employing an event study model that interacted the treatment variables with the full set of fixed year effects. The regression took the form as Eq. 2 below. To satisfy the parallel trends assumption, 
no statistical significance on the first coefficient was expected, which suggested no change associated with Medicaid expansion between the period at least 2 years and 1 year prior to expansion. Statistical significance in later years' coefficients indicated the expansion effected the treatment group with the given poverty level. In addition, we also examined the association of Medicaid expansion with a placebo outcome unrelated to insurance status that would not be affected by the policy. The placebo outcome was set as the probability of getting higher education. The placebo outcome check was performed in the same format as Eq. 1.

$$
\begin{aligned}
\text { Uninsured }_{i s y}= & \beta_{0}+\beta_{1} \text { Pre } 2 * \text { Povert }_{i s y}+\beta_{3}{\text { Same } 0 * \text { Poverty }_{i s y}} \\
& +\beta_{3}{\text { Post } 1 * \text { Poverty }_{i s y}+\beta_{4} \text { Post } * \text { Poverty }_{i s y}} \\
& +\beta_{5} \gamma_{s y}+\beta_{6} \delta_{i s}+\beta_{7} \eta_{i y}+\beta_{8} \text { Poverty }_{i s y}+\beta_{9} \text { State }_{i y} \\
& +\beta_{10} \text { Year }_{i s}+\beta_{11} X_{i s y}+\epsilon_{i s y}
\end{aligned}
$$

Similar to the main estimating equation (Eq. 1), only the Expanded $_{i s y}$ treatment variable was changed from the main model into a set of time dummies for individuals given the year and state (Pre2, Same0, Post 1 , Post 2 , time Poverty ${ }_{i s y}$, respectively) in Eq. 2. The Pre 2 term was an indicator variable set as 1 and represented at least 2 years before a state expanded Medicaid and 0 otherwise. The second Same0was 1 when in the year a state expanded Medicaid and 0 otherwise. Same algorithm followed for the Post 1 and Post 2 . The omitted category Pre 1 was the year immediately before expansion. Thus, the coefficients on each of these variables gave the change for 2-year before expansion and 2-year post expansion. Other variables in Eq. 2 represented the same state/year fixed effects and control vectors as Eq. 1. Standard errors were clustered at the state level to account for state-level differences and serial autocorrelation. The 7-year data was a multi-year combination of the 1-year PUMS file with appropriate adjustments to the weights and inflation adjustment factors. The significance level for tests was set as 0.05 . The data was weighted by the ACS survey weight and analyses were performed using SAS 9.4 and Stata 12.0.

\section{Results}

Figure 2 presents the trends in the uninsured rate from 2012 to 2018 by poverty level groups. The uninsured rates reduced significantly after the market exchange subsidy and implementation of Medicaid expansion for all poverty levels. Specifically, compared with the uninsured rates in 2012, the uninsured rates in 2018 decreased by $10.75,6.42$, and $1.11 \%$ points for individuals under $138 \%$ FPL, between 138 and $400 \%$ FPL, and above $400 \%$ FPL, respectively. Although the uninsured rate decreased for all groups, those under $138 \%$ FPL still had the highest uninsured rates.

Table 1 presents the pre-policy period comparison on demographic and socioeconomic characteristics between states who adopted Medicaid expansion on January 1, 2014 with states who did not adopt the policy at that time. Both adopted and non-adopted states presented similar age and gender distributions with more than $50 \%$ people being over 45 years old and about $51 \%$ female. Majority of the population were married and employed. White was the majority race/ethnicity while Black made up $8 \%$ in adopted states and $14 \%$ in nonadopted states. Overall, Medicaid expansion states had a higher education level (35\% received Bachelors' degree or higher). Expanded states also had a much higher mean FPL than states without expansion (423\% FPL vs.

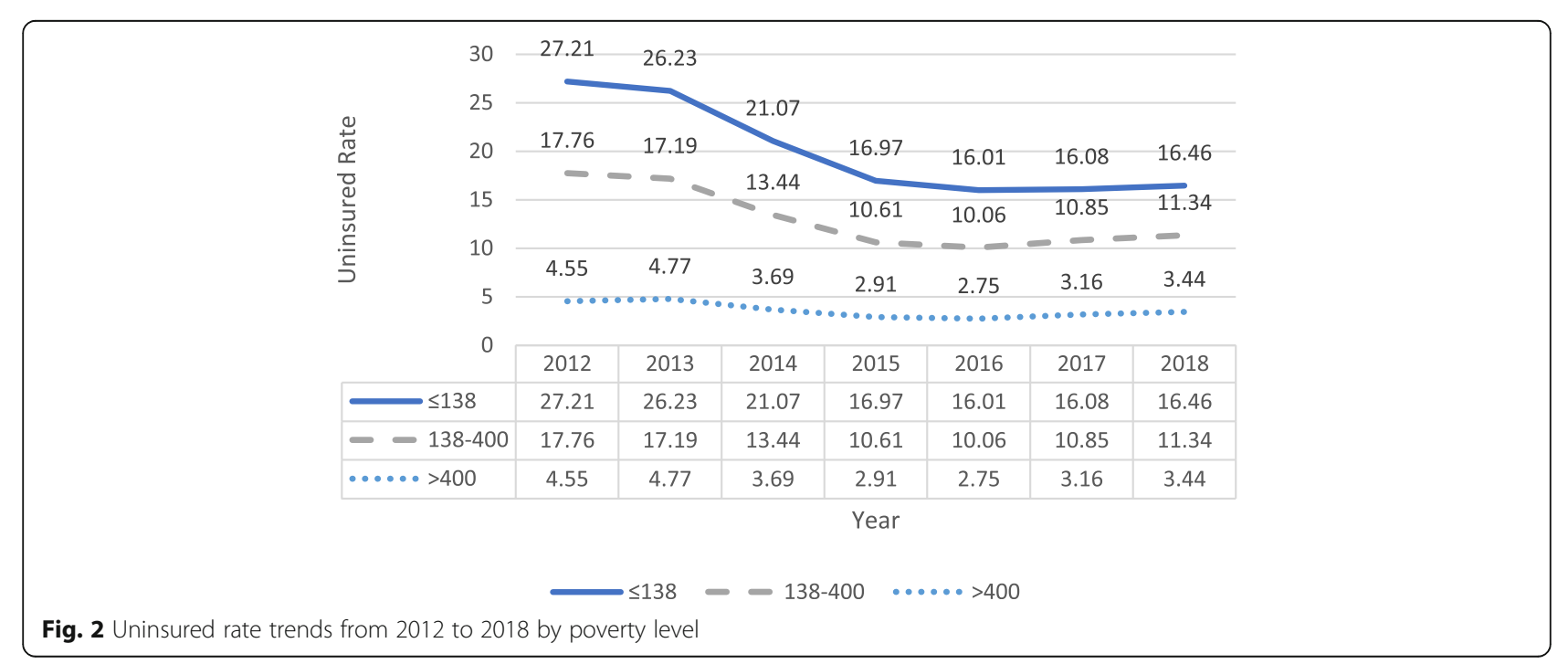


Table 1 Demographic Characteristics among adopted states and non-adopted states before 2014

\begin{tabular}{|c|c|c|c|c|c|c|}
\hline & & \multicolumn{2}{|c|}{ Adopted on $2014 / 1 / 1$} & \multicolumn{2}{|c|}{ Not adopted on $2014 / 1 / 1$} & \multirow[t]{2}{*}{$P$-value } \\
\hline & & $\mathrm{N}$ & $\%$ & $\mathrm{~N}$ & $\%$ & \\
\hline \multirow[t]{4}{*}{ age } & $26-34$ & 293,965 & 19.93 & 285,258 & 19.58 & $<.0001$ \\
\hline & $35-44$ & 332,162 & 22.52 & 330,374 & 22.68 & \\
\hline & $45-54$ & 423,514 & 28.71 & 417,549 & 28.66 & \\
\hline & $55-65$ & 425,556 & 28.85 & 423,645 & 29.08 & \\
\hline \multirow[t]{2}{*}{ Gender } & Female & 754,787 & 51.17 & 745,841 & 51.2 & 0.5939 \\
\hline & Male & 720,410 & 48.83 & 710,985 & 48.8 & \\
\hline \multirow[t]{4}{*}{ Race/Ethnicity } & White & $1,061,213$ & 71.94 & $1,088,222$ & 74.7 & $<.0001$ \\
\hline & Black & 118,943 & 8.06 & 199,898 & 13.72 & \\
\hline & Hispanic & 160,728 & 10.9 & 108,649 & 7.46 & \\
\hline & Other & 134,313 & 9.1 & 60,057 & 4.12 & \\
\hline \multirow[t]{3}{*}{ Marital Status } & Married & 896,448 & 60.77 & 903,190 & 62 & $<.0001$ \\
\hline & Widowed/Divorced/Separated & 257,902 & 17.48 & 285,617 & 19.61 & \\
\hline & Never married & 320,847 & 21.75 & 268,019 & 18.4 & \\
\hline \multirow[t]{3}{*}{ Education Level } & Less than high school & 124,888 & 8.47 & 140,152 & 9.62 & $<.0001$ \\
\hline & High school graduate, GED, or alternative & 837,969 & 56.8 & 887,294 & 60.91 & \\
\hline & Bachelor's degree or higher & 512,340 & 34.73 & 429,380 & 29.47 & \\
\hline \multirow[t]{4}{*}{ Employment Status } & Unemployed & 79,270 & 5.37 & 71,171 & 4.89 & $<.0001$ \\
\hline & Employed & $1,056,853$ & 71.64 & $1,018,495$ & 69.91 & \\
\hline & Not in labor force & 339,074 & 22.98 & 367,160 & 25.2 & \\
\hline & & Mean & Standard Error & Mean & Standard Error & \\
\hline Federal Poverty Level & & 423.06 & 508.10 & 368.80 & 434.30 & $<.0001$ \\
\hline
\end{tabular}

329 \% FPL, respectively). Chi-square tests for categorical variables and two sample t-test for continuous variables were performed to explore the differences between adopted and non-adopted states by year 2014. All characteristics except gender showed statistically significant differences among adopted states and non-adopted states before Medicaid expansion took effect.

Table 2 displays the results of the two regressions based on the triple-D design, each with a basic linear model and multivariate linear probability model with controlled covariates. For the first basic regression, those under $138 \%$ FPL versus those above $138 \%$ FPL, there was a $2.44 \%$ point decrease in uninsured risk after expansion among those under $138 \%$ FPL in adopted states versus control states. Controlling for socio-demographic characteristics, there was a decrease of $2.54 \%$ points in uninsured risk which almost doubled the uncontrolled model's reduction. For the second regression comparing those under $138 \%$ FPL and above $400 \%$ FPL, the unadjusted model showed a decrease of $3.09 \%$ points in the uninsured probability while the adjusted model showed a decrease of $3.19 \%$ points. Results also indicated individuals under $138 \%$ FPL were still $12.78 \%$ points and $19.77 \%$ points more likely of being uninsured under expansion compared to those above $138 \%$ FPL and above $400 \%$ FPL, respectively. Further, as age increased, the likelihood of being insured also increased. Among all race and ethnicities, compared with whites, Hispanics were the most unlikely to have insurance.

Figure $3 \mathrm{a}$ and $\mathrm{b}$ present event study graphs that meet the parallel trends assumption in the pre-policy period between the adopted states and the control states. The graphs also showed that if Medicaid expansion had not occurred, changes in insurance coverage would have not been correlated with pre-treatment uninsured rates. The placebo outcome robustness check reported insignificant results with $p$-values equal to 0.634 for regression $\leq$ $138 \% \mathrm{FPL}$ and $>138 \% \mathrm{FPL}$, and 0.545 for regression $\leq$ $138 \%$ FPL and $>400 \%$ FPL, respectively. With both regressions' p-values greater than 0.05 , placebo checks showed that Medicaid expansion did not have an impact on our outcome, unrelated to the policy.

\section{Discussion}

After a long post-Medicaid expansion period, our study examined the effects of the dynamic adoption of Medicaid expansion on poverty disparities in health insurance coverage at the national level. Findings from this study demonstrate that trends in the uninsured rate for each FPL group decreased from 2012 to 2018. Across all 7 


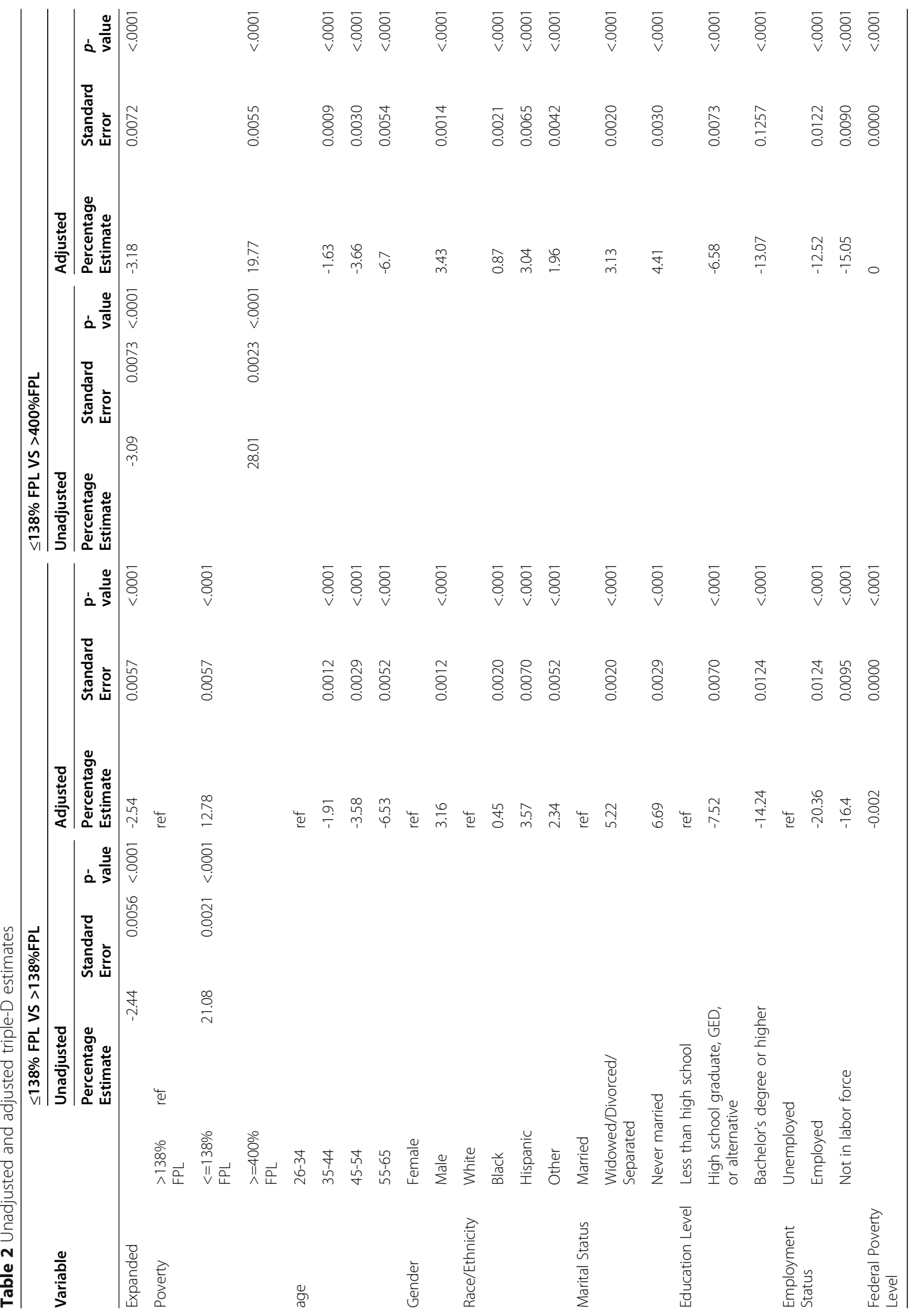




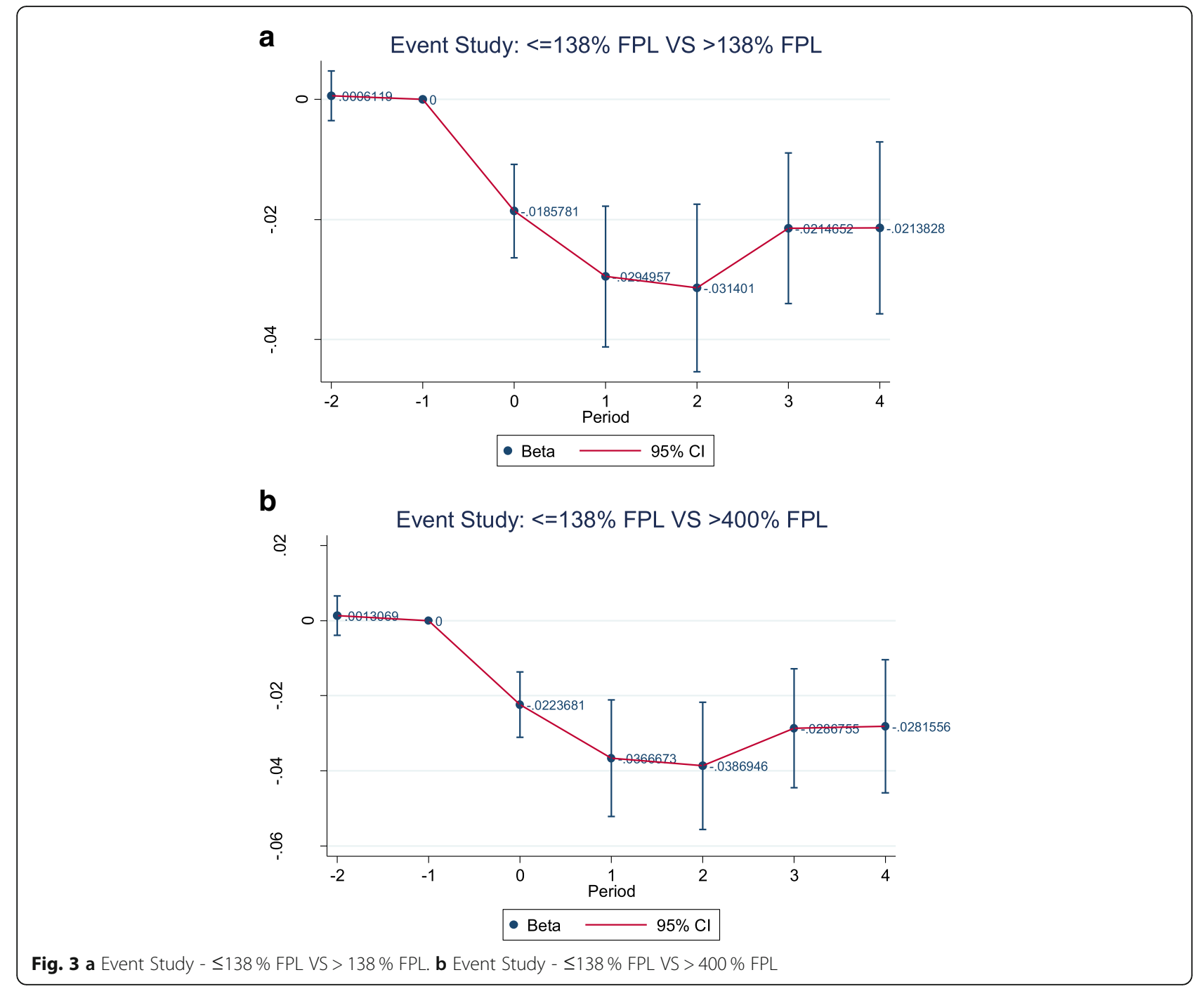

years, the "over $400 \%$ FPL" group continuously had the lowest uninsured rate while the "under $138 \%$ FPL" group had the highest uninsured rate. For all FPL groups, the uninsured rates were reduced significantly after implementation of Medicaid expansion. Through the triple-D design, both regressions showed a significant reduction in uninsured risk was due to Medicaid expansion.

This study documented that a large increase in Medicaid eligibility was associated with a significant decrease in the uninsured rate during the study period. We also found that the population with the largest coverage gains from expansion were those aged 55-64 years old, welleducated, and employed. For example, our results found that individuals with bachelor's degree or higher were $14.24 \%$ less likely to be uninsured compared with individuals who had less than a high school education. These findings may influence states' decisions with respect to Medicaid expansion.
Previous studies have identified the benefits of Medicaid expansion on health insurance coverage among individuals with low socioeconomic status. However, this study further added to the literature with novel contributions. The overall results of this study extended the literature in several ways. First, this paper presented new evidence used a large national level survey and longer time frame to assess the association of expansion and insurance coverage. Many datasets such as the Behavioral Risk Factor Surveillance System, Gallup-Healthways Well-Being Index (daily national telephone survey), and federal survey data, have been used to assess the socioeconomic disparities in health care access $[43-45,56]$. Studies using these datasets found that health care access for people in lower socioeconomic strata had higher improvement in states that expanded eligibility for Medicaid under the ACA than states that did not. Socioeconomic disparities in health care access narrowed 
significantly under the ACA. Rather than assessing the early stage of the first- and second- year of Medicaid expansion, our study reached similar conclusions using comparable study design but in unrelated, populationbased survey data. In addition, to report the association between Medicaid expansion and insurance coverage among low-income populations, our study demonstrated a more precise estimation of this relationship by using a varying intensity policy variable and eliminating the effect of parents' health insurance coverage for young adults under 26 years of age and the ACA premium subsidy. Sommers et al. found that increasing insurance coverage increased health care utilizations by conducting a triple-D analysis of survey data from November 2013 through December 2015 on US citizens ages 19 to 64 years old with incomes below 138 \% FPL in Kentucky, Arkansas, and Texas [45]. Our findings were consistent with this state-level research and strengthened the conclusion at a national level that poverty disparities were narrowed by increases in insurance coverage.

Secondly, the triple-D estimates started with the average time changes for the population under $138 \% \mathrm{FPL}$ in the expanded states, then netted out the change in means for the population under $138 \%$ FPL in the control states and the change in means for the population over $138 \%$ FPL in the expanded states. This controlled for two types of potentially confounding trends: changes in insurance coverage for the population under $138 \% \mathrm{FPL}$ across states (that would have nothing to do with the policy) and changes in health status of all people living in the expanded states (possibly due to other state policies that affect everyone's insurance status, or statespecific changes in the economy that affect everyone's insured rate). The triple-D design allowed us to estimate the casual impact of Medicaid expansion and contributed to an evidence-based policy decision-making process.

This study is not without its limitations. First, due to data availability, we were only able to estimate the effects up until 2018. Therefore, some states, such as Louisiana, had a very short post-policy period. Additionally, for states that adopted Medicaid expansion after 2018, their effects were not seen. As future waves of data become available, it is worthwhile to revisit these estimates. Another limitation of this study is that detailed policy differences within each state were not considered. Some states had different eligibility criteria for Medicaid prior to the adoption of expansion. In other words, the policy impact varied in the adopted states due to the beforeadoption eligibility criteria. Further studies may examine these differences to get the unbiased policy effect. Lastly, ACS did not contain detailed health information such as disease conditions and healthcare utilization. Controlling for pre-conditions of individuals, could improve the precision of our estimates, and with specific healthcare utilization measurements, we could better understand the direct impact of this policy on healthcare utilization.

\section{Conclusions}

In this study, health insurance coverage improved substantially among populations with income less than 138 \% FPL. Overall, Medicaid expansion has made impressive strides in reducing health inequity with increasing access to health insurance coverage among lowincome populations. Our findings are consistent with previous literature and reflect the achievement of Medicaid expansion's goal, making healthcare accessible for low-income populations. However, individuals under $138 \%$ FPL are still more likely to be uninsured.

Unlike other developed countries, the US does not have universal health insurance programs in which the government plays a dominant role. One major challenge of the US healthcare system is providing equitable access to care. Disparities in health outcomes by income status are persistent and hard to reduce in the US. Therefore, the ACA and Medicaid expansion are critical to expand health insurance to improve overall quality of life for US citizens. Based on our findings, adequate access to health care services still falls short and there is still a long way to go to achieve healthcare equity. Healthcare professionals and policy makers should continue to advocate for increased coverage for low-income populations. Reducing health inequity in health insurance coverage is achievable but will require better outreach to the remaining uninsured, particularly among vulnerable groups with historically low and disproportionate uninsured rates.

\section{Abbreviations}

ACA: Affordable Care Act; ACS: American Community Survey; FPL: Federal Poverty Level; PUMS: Public Use Microdata Sample files; Triple-D design: Differences-in-differences-in-differences design; DC: District of Columbia; DE: Delaware; IN: Indiana; MA: Massachusetts; ME: Maine; NY: New York; TN: Tennessee; VT: Vermont; WI: Wisconsin

\section{Acknowledgements}

Not applicable.

\section{Authors' contributions}

Yilu Lin did the analysis and drafted the manuscript. Alisha Monnette and Lizheng Shi contributed to the critical revision of the manuscript for important intellectual content. The author(s) read and approved the final manuscript.

\section{Funding}

The authors received no financial support for the research, authorship, and/ or publication of this article.

Availability of data and materials

The American Community Survey data is public data available on the ACS official website. 


\section{Declarations}

\section{Ethics approval and consent to participate}

Not applicable. This is a data analysis only study using de-identified data.

\section{Consent for publication}

Not applicable.

\section{Competing interests}

The authors declared no conflicts of interest with respect to the research, authorship, and/or publication of this article.

Received: 22 February 2021 Accepted: 1 June 2021

Published online: 26 July 2021

\section{References}

1. Distribution of the Total Population by Federal Poverty Level (above and below 200\% FPL) The Henry J. Kaiser Family Foundation. 2019. Retrieved Mar 10 2020, from: https://www.kff.org/other/state-indicator/population-upto-200-fpl/?currentTimeframe=0\&sortModel=\%7B\%22colld\%22:\%22Loca tion\%22,\%22sort\%22:\%22asc\%22\%7D

2. Hadley J. Sicker and poorer-the consequences of being uninsured: a review of the research on the relationship between health insurance, medical care use, health, work, and income. Med Care Res Rev. 2003;60(2 suppl):3S-75S

3. Schoen C, DesRoches C. Uninsured and unstably insured: the importance of continuous insurance coverage. Health Serv Res. 2000;35(1 Pt 2):187.

4. Satcher D, Fryer GE Jr, McCann J, Troutman A, Woolf SH, Rust G. What if we were equal? A comparison of the black-white mortality gap in 1960 and 2000. Health Aff (Millwood). 2005;24(2):459-64

5. Zsembik BA, Fennell D. Ethnic variation in health and the determinants of health among Latinos. Soc Sci Med. 2005;61(1):53-63.

6. DeNavas-Walt C. Income, poverty, and health insurance coverage in the United States (2005): Diane Publishing; 2010.

7. Cohen RA, Martinez ME, Zammitti EP. Health insurance coverage: early release of estimates from the National Health Interview Survey; 2015.

8. Carman KG, Eibner C, Paddock SM. Trends in health insurance enrollment, 2013-15. Health Aff (Millwood). 2015;34(6):1044-8.

9. Rudowitz R, Musumeci M. The ACA and Medicaid expansion waivers: Kaiser Commission on Medicaid and the Uninsured; 2015.

10. Antonisse L, Garfield R, Rudowitz R, Artiga S. The effects of Medicaid expansion under the ACA: updated findings from a literature review.

11. Hayes SL, Riley P, Radley DC, McCarthy D. Closing the gap: past performance of health insurance in reducing racial and ethnic disparities in access to care could be an indication of future results. New York: Commonwealth Fund; 2015

12. Clemans-Cope L, Kenney GM, Buettgens M, Carroll C, Blavin F. The Affordable Care Act's coverage expansions will reduce differences in uninsurance rates by race and ethnicity. Health Aff (Millwood). 2012;31(5): 920-30.

13. Sealy-Jefferson S, Vickers J, Elam A, Wilson MR. Racial and ethnic health disparities and the Affordable Care Act: a status update. J Racial Ethn Health Disparities. 2015:2(4):583-8.

14. Johnston EM, MCMorrow S, Thomas TW, Kenney GM. ACA Medicaid expansion and insurance coverage among new mothers living in poverty. Pediatrics. 2020;145(5):e20193178. https://doi.org/10.1542/peds.2019-3178 Epub 2020 Apr 15. PMID: 32295817

15. Clapp MA, James KE, Kaimal AJ, Sommers BD, Daw JR. Association of Medicaid expansion with coverage and access to care for pregnant women Obstet Gynecol. 2019;134(5):1066-74. https://doi.org/10.1097/AOG. 0000000000003501 PMID: 31599841.

16. O'Mahen PN, Petersen LA. Effects of state-level Medicaid expansion on veterans health administration dual enrollment and utilization: potentia implications for future coverage expansions. Med Care. 2020;58(6):526-33. https://doi.org/10.1097/MLR.0000000000001327 PMID: 32205790.

17. Stimpson JP, Kemmick Pintor J, McKenna RM, Park S, Wilson FA. Association of Medicaid expansion with health insurance coverage among persons with a disability. JAMA Netw Open. 2019;2(7):e197136. https://doi.org/10.1001/ja manetworkopen.2019.7136 PMID: $31314115 ;$ PMCID: PMC6647921.

18. Rajbhandari-Thapa J, Zhang D, MacLeod KE, Thapa K. Impact of Medicaid expansion on insurance coverage rates among adult populations with low income and by obesity status. Obesity (Silver Spring). 2020;28(7):1219-23. https://doi.org/10.1002/oby.22793 Epub 2020 Apr 18. PMID: 32304356.

19. DiGiulio A, Haddix M, Jump Z, Babb S, Schecter A, Williams KS, et al. State Medicaid expansion tobacco cessation coverage and number of adult smokers enrolled in expansion coverage - United States, 2016. MMWR Morb Mortal Wkly Rep. 2016;65(48):1364-9. https://doi.org/10.15585/mmwr. mm6548a2 PMID: 27932786

20. Stimpson JP, Wilson FA. Medicaid expansion improved health insurance coverage for immigrants, but disparities persist. Health Aff (Millwood). 2018; 37(10):1656-62. https://doi.org/10.1377/hlthaff.2018.0181 PMID: 30273021.

21. Wright BJ, Conlin AK, Allen HL, Tsui J, Carlson MJ, Li HF. What does Medicaid expansion mean for cancer screening and prevention? Results from a randomized trial on the impacts of acquiring Medicaid coverage. Cancer. 2016;122(5):791-7. https://doi.org/10.1002/cncr.29802 Epub 2015 Dec 9. PMID: 26650571; PMCID: PMC6193753.

22. Nikpay SS, Tebbs MG, Castellanos EH. Patient protection and Affordable Care Act Medicaid expansion and gains in health insurance coverage and access among cancer survivors. Cancer. 2018;124(12):2645-52. https://doi. org/10.1002/cncr.31288 Epub 2018 Apr 16. PMID: 29663343.

23. Toyoda Y, Oh EJ, Premaratne ID, Chiuzan C, Rohde CH. Affordable Care Act state-specific Medicaid expansion: impact on health insurance coverage and breast Cancer screening rates. J Am Coll Surg. 2020:S1072-7515(20)30213-1. https://doi.org/10.1016/j.jamcollsurg.2020.01.031 Epub ahead of print. PMID: 32272206 .

24. Weiner AB, Jan S, Jain-Poster K, Ko OS, Desai AS, Kundu SD. Insurance coverage, stage at diagnosis, and time to treatment following dependent coverage and Medicaid expansion for men with testicular cancer. PLoS One. 2020;15(9):e0238813. https://doi.org/10.1371/journal.pone.0238813 PMID: 32936794; PMCID: PMC7494102.

25. Osazuwa-Peters N, Barnes JM, Megwalu U, Adjei Boakye E, Johnston KJ, Gaubatz ME, et al. State Medicaid expansion status, insurance coverage and stage at diagnosis in head and neck cancer patients. Oral Oncol. 2020;110: 104870. https://doi.org/10.1016/j.oraloncology.2020.104870 Epub 2020 Jul 3. PMID: 32629408

26. Baugher AR, Finlayson T, Lewis R, Sionean C, Whiteman A, Wejnert C, et al. Health care coverage and Preexposure Prophylaxis (PrEP) use among men who have sex with men living in 22 US cities with vs without Medicaid expansion, 2017. Am J Public Health. 2021;111(4):743-51. https://doi.org/1 0.2105/AJPH.2020.306035 Epub 2021 Jan 21. PMID: 33476242; PMCID: PMC7958013.

27. Zuvekas SH, McClellan CB, Ali MM, Mutter R. Medicaid expansion and health insurance coverage and treatment utilization among individuals with a mental health condition. J Ment Health Policy Econ. 2020;23(3):151-82 PMID: 33411677

28. Olfson M, Wall M, Barry CL, Mauro C, Mojtabai R. Impact of Medicaid expansion on coverage and treatment of low-income adults with substance use disorders. Health Aff (Millwood). 2018;37(8):1208-15. https://doi.org/1 0.1377/hlthaff.2018.0124 PMID: 30080455; PMCID: PMC6190698

29. Fry CE, Sommers BD. Effect of Medicaid expansion on health insurance coverage and access to care among adults with depression. Psychiatr Serv. 2018;69(11):1146-52. https://doi.org/10.1176/appi.ps.201800181 Epub 2018 Aug 28. PMID: 30152271; PMCID: PMC6395562.

30. McMorrow S, Gates JA, Long SK, Kenney GM. Medicaid expansion increased coverage, improved affordability, and reduced psychological distress for low-income parents. Health Aff (Millwood). 2017;36(5):808-18. https://doi. org/10.1377/hlthaff.2016.1650 PMID: 28461346.

31. Soni A, Hendryx M, Simon K. Medicaid expansion under the Affordable Care Act and insurance coverage in rural and urban areas. J Rural Health. 2017; 33(2):217-26. https://doi.org/10.1111/jrh.12234 Epub 2017 Jan 23. PMID: 28114726

32. Stimpson JP, Kemmick Pintor J, Wilson FA. Association of Medicaid expansion with health insurance coverage by marital status and sex. PLoS One. 2019;14(10):e0223556. https://doi.org/10.1371/journal.pone.0223556 PMID: 31644546; PMCID: PMC6808332.

33. Selden TM, Abdus S, Keenan PS. Insurance coverage of ambulatory care visits in the last six months of 2011-13 and 2014, by Medicaid expansion status. 2016 Oct. In: Statistical brief (medical expenditure panel survey (US)) [internet]. Rockville: Agency for Healthcare Research and Quality (US); 2001. STATISTICAL BRIEF \#494. PMID: 28422467.

34. Zogg CK, Scott JW, Bhulani N, Gluck AR, Curfman GD, Davis KA, et al. Impact of Affordable Care Act insurance expansion on pre-hospital access to care: 
changes in adult perforated appendix admission rates after Medicaid expansion and the dependent coverage provision. J Am Coll Surg. 2019; 228(1):29-43.e1. https://doi.org/10.1016/j.jamcollsurg.2018.09.022 Epub 2018 Oct 22. PMID: 30359835.

35. Bloodworth R, Chen J, Mortensen K. Variation of preventive service utilization by state Medicaid coverage, cost-sharing, and Medicaid expansion status. Prev Med. 2018;115:97-103. https://doi.org/10.1016/j. ypmed.2018.08.020 Epub 2018 Aug 23. PMID: 30145344.

36. Gordon SH, Sommers BD, Wilson IB, Trivedi AN. Effects of Medicaid expansion on postpartum coverage and outpatient utilization. Health Aff (Millwood). 2020;39(1):77-84. https://doi.org/10.1377/hlthaff.2019.00547 PMID: 31905073; PMCID: PMC7926836.

37. Benitez JA, Creel L, Jennings J'A. Kentucky's Medicaid expansion showing early promise on coverage and access to care. Health Aff. 2016;35(3):528-34.

38. Freedman S, Richardson L, Simon KI. Learning from waiver states: coverage effects under Indiana's HIP Medicaid expansion. Health Aff (Millwood). 2018; 37(6):936-43. https://doi.org/10.1377/hlthaff.2017.1596 PMID: 29863935.

39. Huguet N, Hoopes MJ, Angier H, Marino M, Holderness H, DeVoe JE. Medicaid expansion produces Long-term impact on insurance coverage rates in community health centers. J Prim Care Community Health. 2017; 8(4):206-12. https://doi.org/10.1177/2150131917709403 Epub 2017 May 17. PMID: 28513249; PMCID: PMC5665709.

40. Blumberg LJ, Holahan J. Early experience with the ACA: coverage gains, pooling of risk, and Medicaid expansion. J Law Med Ethics. 2016;44(4):53845. https://doi.org/10.1177/1073110516684784 PMID: 28661254.

41. Selden TM, Lipton BJ, Decker SL. Medicaid expansion and marketplace eligibility both increased coverage, with trade-offs in access, affordability. Health Aff (Millwood). 2017;36(12):2069-77. https://doi.org/10.1377/hlthaff.2 017.0830 PMID: 29200332.

42. Frean M, Gruber J, Sommers BD. Premium subsidies, the mandate, and Medicaid expansion: coverage effects of the Affordable Care Act. J Health Econ. 2017;53:72-86. https://doi.org/10.1016/j.jhealeco.2017.02.004 Epub 2017 Mar 6. PMID: 28319791.

43. Courtemanche C, Marton J, Ukert B, Yelowitz A, Zapata D. Early impacts of the Affordable Care Act on health insurance coverage in Medicaid expansion and non-expansion states. J Policy Anal Manage. 2017:36(1):178210. https://doi.org/10.1002/pam.21961 PMID: 27992151.

44. Decker SL, Lipton BJ, Sommers BD. Medicaid expansion coverage effects grew in 2015 with continued improvements in coverage quality. Health Aff (Millwood). 2017;36(5):819-25. https://doi.org/10.1377/hlthaff.2016.1462 PMID: 28461347.

45. Sommers BD, Blendon RJ, Orav EJ, Epstein AM. Changes in utilization and health among low-income adults after Medicaid expansion or expanded private insurance. JAMA Intern Med. 2016;176(10):1501-9. https://doi.org/1 0.1001/jamainternmed.2016.4419 PMID: 27532694.

46. Andersen RM. Revisiting the behavioral model and access to medical care: does it matter? J Health Soc Behav. 1995;36(1):1-10.

47. Mulcahy A, Harris K, Finegold K, Kellermann A, Edelman L, Sommers BD. Insurance coverage of emergency care for young adults under health reform. N Engl J Med. 2013;368(22):2105-12.

48. Understanding and Using American Community Survey Data. 2019 Retrieved April 12, 2021, from https:/www.census.gov/content/dam/ Census/ibrary/publications/2019/acs/acs_aian_handbook_2019.pdf

49. Afendulis CC, He Y, Zaslavsky AM, Chernew ME. The impact of Medicare part D on hospitalization rates. Health Serv Res. 2011;46(4):1022-38.

50. Domino ME, Martin BC, Wiley-Exley E, Richards S, Henson A, Carey TS, et al. Increasing time costs and copayments for prescription drugs: an analysis of policy changes in a complex environment. Health Serv Res. 2011;46(3):90019.

51. Chua KP, Sommers BD. Changes in health and medical spending among young adults under health reform. JAMA. 2014;311(23):2437-9.

52. Sommers BD, Kronick R. The Affordable Care Act and insurance coverage for young adults. JAMA. 2012;307(9):913-4.

53. Akosa Antwi Y, Moriya AS, Simon K. Effects of federal policy to insure young adults: evidence from the 2010 Affordable Care Act's dependent-coverage mandate. Am Econ J Econ Pol. 2013:5(4):1-28.

54. Status of state Medicaid expansion decisions: Interactive map. Retrieved April 21, 2021, from https://www.kff.org/medicaid/issue-brief/status-of-statemedicaid-expansion-decisions-interactive-map/

55. APSE. 2019. Retrieved May 3, 2021, from https://aspe.hhs.gov/
56. Sommers BD, Gunja MZ, Finegold K, Musco T. Changes in self-reported insurance coverage, access to care, and health under the Affordable Care Act. JAMA. 2015;314(4):366-74.

57. Griffith K, Evans L, Bor J. The Affordable Care Act reduced socioeconomic disparities in health care access. Health Aff (Millwood). 2017;36(8):1503-10.

58. Karletsos D, Stoecker C. Impact of Medicaid expansion on PrEP utilization in the US: 2012-2018. AIDS Behav. 2020:1-9.

59. Stoecker $C$, et al. Association of nonprofit hospitals' charitable activities with unreimbursed Medicaid care after Medicaid expansion. JAMA Netw Open. 2020;3(2):e200012.

\section{Publisher's Note}

Springer Nature remains neutral with regard to jurisdictional claims in published maps and institutional affiliations.
Ready to submit your research? Choose BMC and benefit from:

- fast, convenient online submission

- thorough peer review by experienced researchers in your field

- rapid publication on acceptance

- support for research data, including large and complex data types

- gold Open Access which fosters wider collaboration and increased citations

- maximum visibility for your research: over $100 \mathrm{M}$ website views per year

At BMC, research is always in progress.

Learn more biomedcentral.com/submissions 